\title{
Keynotes
}

\section{Sexual abuse in psychiatric hospitals: developing policies to aid prevention}

\author{
Fiona Subotsky, Consultant Child Psychiatrist, King's College Hospital, \\ London SE5 9RS
}

Over the last few years, there has been a considerable increase in public awareness of the sexual abuse of children and the incidence of violence, often with sexual aspects, to women in their homes and elsewhere. Questions about such occurrences are now frequently asked as part of the psychiatric assessment of women patients (Palmer et al, 1992). However, only comparatively recently has the issue of sexual assault within psychiatric provision begun to be raised (Gath, 1989; Subotsky, 1991; Tonks, 1992).

In 1989, two cases of alleged sexual assault between patients were reported on the acute inpatient psychiatric wards of an inner-city general hospital. Staff found such issues difficult to handle for many reasons, including on the one hand an idea that it was old-fashioned to attempt to prevent sexual relationships, and on the other that it was difficult to know when to consider potentially criminal the anti-social behaviour of mentally disturbed adults.

It was decided that debate involving staff, patients, and concerned outsiders (the Community Health Council, and the local Women and Mental Health Forum), might both raise consciousness and contribute to the development of policies which could help reduce the likelihood of sexual assault.

The resulting (slightly simplified) policies are presented, not as final blueprints, but as an example for other staff groups to discuss and build on when facing similar issues.

\section{A. Policy on consenting sexual activity on the in-patient wards \\ 1. Relationships}

Close relationships between patients are not disapproved of, but the in-patient wards are intended for relatively short stays only and do not contain adequate facilities to support full sexual relationships.

In the acute phase of illness some people may become involved in sexual relationships they may later regret. With others, the development of close interpersonal relationships might be to some degree beneficial, but the social skills to achieve this acceptably may be deficient.

\section{Counselling and education}

When staff are aware of the development of a sexual relationship between in-patients they should exercise discretion and concern in the support they offer. Sometimes the social worker may be able to help patients pursue their relationships more appropriately outside the ward environment.

Wherever possible, people should be encouraged and supported to use outside services and facilities for counselling and the supply of contraceptives. Information on such services should be permanently displayed on the ward notice-boards and given in the patients' handbook.

Sexual education should be considered as part of each care plan, and offered on both an individual and group basis by appropriately trained staff, as part of general health and life skills education.

\section{Training}

All staff will need training in this area.

\section{B. Policy on the prevention of sexual harassment and assault on the in-patient wards}

\section{Principles}

All patients have a right to the provision of a safe and secure environment when they are admitted to in-patient facilities.

The health authority is committed, as part of its equal opportunities policy, to respecting the privacy and dignity of patients, to ending sexual harassment and to ensuring no service user receives less favourable treatment on the grounds of being a gay man or lesbian.

Sexual behaviour, whether action or comment, which threatens or discomforts others will not be 
tolerated. This includes harassment on the grounds of sexual identity.

The above should be made clear to all staff, patients and visitors.

\section{General environment}

Many users of psychiatric services, especially women, have suffered sexual abuse previously, and abuse can occur on in-patient wards from other patients and even staff. It is even difficult for the victim to complain when in the relatively powerless position of "psychiatric patient", so complaints must be constructively received and reported.

There should be staff of each gender on each shift.

Patients and visitors of the opposite gender should not be allowed into the male and female dormitories. Alternative arrangements for privacy of visiting should be made.

The female dormitories should have staff supervision if being used.

The use of single-sex discussion groups has been successful in bringing up suggestions and should be continued.

\section{At risk assessment - vulnerability and dangerousness}

When people become disturbed as a consequence of mental illness, they are not always in control of their sexual behaviour. Others may have a low level of social skills in the area of interpersonal relationships. In such circumstances, people should be given assistance to reduce their symptoms and improve their mental health and social skills.

Consideration to each patient's vulnerability and dangerousness should be made in the multidisciplinary care plan; close or special observation may be appropriate. If a patient is identified as constituting an acute sexual threat, there should be an immediate meeting of members of the multidisciplinary team to agree an appropriate course of action.

\section{Procedure in the event of alleged or apparent sexual assault}

\section{Immediate}

The safety of the patient/s must be secured first, and the senior nurse on the ward notified to coordinate the ensuing action.

\section{The victim}

The victim should be taken immediately to a quiet room, and interviewed initially briefly by the nurse on duty who is most familiar with the patient, or by the most senior nurse on duty. The patient may ask to see a nurse of the same sex, and this request could be met.

The following information should be obtained:

(i) name/description of person alleged to have committed the assault

(ii) brief description of circumstances of assault including date, time and place

(iii) names of witnesses, if any.

Any immediate action necessary should be taken, and then more details sought, offering a choice to the patient of interviewers, and who he/she would like to be present, such as a ward nurse or community nurse, his/her doctor, friend, relative, social worker, or a rape crisis counsellor.

Immediate medical attention may be necessary, e.g. for injury, but should not duplicate forensic examination. Later medical needs may include pregnancy testing, and an early appointment with the Sexually Transmitted Diseases clinic.

Arrangements for further counselling and support to the patient assaulted should be made later, using either hospital or non-hospital staff according to the patient's preference. Phone numbers of appropriate organisations should be maintained on the wards.

\section{The perpetrator}

If the person who is alleged to have committed the assault is another patient, that patient should be made aware of the allegation, and interviewed by the most appropriate staff member. A quiet room should be used for the purpose and consideration should be given to the mental state of the person in determining whether additional members of staff should be present.

The immediate and long-term psychiatric management will need urgent review, and include consideration of the use of "intensive care", and of separation from the victim. An appointment with the STD clinic may be appropriate.

\section{Notification}

The duty psychiatrist should be informed as soon as possible, and following the initial interview the patient's consultant should be informed, as should the nearest relative (with the agreement of the patient), and the on-call nurse manager.

\section{Forensic issues}

During the interview the patient should be advised that he/she may request the involvement of the police who should then be informed by the patient or by the nurse in charge of the ward, if the patient is unable to do so. The patient should be given a list of contacts of solicitors and of rape crisis centres.

If the police are called, consideration should be given to whether the victim and alleged perpetrator 
should be interviewed and/or receive forensic medical examination on ward or police premises. Quiet facilities should be made available on the ward and an appropriate member of the nursing staff should be available while the patients are being seen by police officers.

\section{Additional notes}

Staff should be aware that not all sexual assaults are by a man on a woman, and should treat allegations of other types of assault with an equal gravity.

In the event of a sexual assault on a member of staff by a patient or visitor the Incident Room Procedure should be followed and the police informed as appropriate.

If there is an allegation that a member of staff has committed a sexual assault, this must be reported not only to the senior member of the profession concerned but also to the Unit Manager immediately, and will be fully investigated under the Disciplinary Procedure.

\section{References}

GATH, A. (1989) Statement on abuse and harassment within psychiatric hospitals. Psychiatric Bulletin, 13, 460.

Palmer, R. L. Chaloner, D. A. \& Oppenheimer, R. (1992) Childhood sexual experiences with adults reported by fernale psychiatric patients. British Journal of Psychiatry. $160,261-265$.

SuBotsky, F. (1991) Issues for women in the development of mental health services. British Journal of Psychiatry, (suppl 10), 17-21.

Tonks, A. (1992) Women patients vulnerable in mixed psychiatric wards. British Medical Journal, 304, 1331.

\title{
Original articles
}

\section{Guardianship - a case for wider use}

\author{
R. L. Symonds, Consultant Psychiatrist, Medway Hospital, Gillingham, \\ Kent ME7 5NY
}

Few psychiatrists have had much experience of guardianship (Section 7, Mental Health Act, 1983). The two cases described have been successful and suggest wider use of this section. It seems apposite in view of the Royal College of Psychiatrists' advice on discharge of patients from hospital, and discussion on a community treatment order; the continuing drive to community care, as codified in the 'Care Programme Approach'; and the need in the future to treat increasingly disturbed individuals in the community as envisaged in the Reed report.

\section{Case studies}

Case 1

AS is a 55-year-old single man from the Sikh culture, admitted to the acute unit some three years earlier just before Christmas. His employers, a local factory, feared he would wait outside the factory over the Christmas holiday period, and consequently die of exposure. It was obvious that AS was suffering from residual schizophrenia. A solitary, selfneglected man, he was troubled with continuous auditory hallucinosis, was taciturn and concrete in thinking. He owned a house in a derelict condition in the distant town, but spent at most only a few hours a week there, the rest of the time spent in the factory where he was employed in tedious repetitive machine maintenance. He was admitted several times over the next three years until, when he refused to leave the factory at all and slept all night standing against a wall, he was retired with redundancy pay. His ample savings were a cause for concern as he had previously been robbed, and thus he was brought under the provisions of the Court of Protection. Although his house was purchased compulsorily by the local authority because it was a hazard, he steadfastly refused to consider sheltered accommodation and did not continue neuroleptic medication when discharged.

AS was made the subject of guardianship to ensure that he lived in a private residential home, found for him by the 